\title{
APPLICATION OF BIM FOR SUPPORTING DECISION- MAKING RELATED TO LOGISTICS IN PREFABRICATED BUILDING SYSTEMS
}

\author{
Fernanda S. Bataglin ${ }^{1}$, Daniela D. Viana ${ }^{2}$, Carlos T. Formoso ${ }^{3}$ and Iamara R. Bulhões ${ }^{4}$
}

\begin{abstract}
Managing industrialised construction requires an accurate synchronisation of design, manufacturing and assembly processes. Considering the high uncertainty and the interdependences between different processes on site, it is important to consider the status of the construction site in the planning and control process. Understanding the demands of site assembly in terms of components is a key step for integrating fabrication and site assembly. One possible approach is to use Building Information Modelling (BIM) for planning the logistics operations of prefabricated building systems.

The aim of this paper is to describe an application of BIM 4D modelling for supporting the planning and control process of logistics operations for Engineer-toorder (ETO) concrete prefabricated structures. Design Science Research was the methodological approach adopted in this investigation, which involved an empirical study carried out in partnership with a company that design, produces and assemble prefabrication concrete structures. The main contribution of this investigation is on how to increase the reliability of information exchanges by concentrating product and process information in a BIM model. Also, some guidelines on how to plan loading and unloading operations, and how to use BIM to assess changes in production plans, considering the logistics impacts.
\end{abstract}

Keywords: Industrialised construction, logistics process, 4D BIM simulation, planning loads, lean construction.

\section{INTRODUCTION}

Building projects have become increasingly complex due to several factors: need to increase building performance, product flexibility, high uncertainty in some markets, and the large number of specialists involved. The growing complexity, associated with the need to reduce project duration, reduce costs and improve working conditions have encouraged the adoption of prefabricated building components and systems, which are often produced offsite. Differently from the idea of mass-producing off-the-shelf parts, this type of industrialisation requires customised design and fabrication, being similar to Engineer-toorder (ETO) production systems in manufacturing (Eastman et al., 2011). In this type of production system, design and production do not start until a customer order is confirmed (Powell et al., 2014).

$1 \quad$ M.Sc. Student, School of Engineering, Building Innovation Research Unit (NORIE), Federal University of Rio Grande do Sul (UFRGS), Porto Alegre, Brazil, fernanda.saidelles@gmail.com

2 Assistant Professor, Interdisciplinary Department, CLN, UFRGS, Porto Alegre, Brazil, danidietz@gmail.com

Professor, School of Engineering NORIE, UFRGS, Porto Alegre, Brazil, formoso@ufrgs.br

Assistant Professor, Interdisciplinary Department, CLN-UFRGS, Porto Alegre, Brazil, iamara.bulhoes@ufrgs.br 
Production planning and control in this type of production system plays the role of coordinating different types of flows (design information, fabrication, logistics operations, and site assembly), in an environment that usually has a high level of uncertainty (Viana, 2015). In fact, the scope of planning and control for prefabricated building systems tends to be different from traditional construction. A major challenge in the management of prefabricated building systems is to avoid stoppages and the increase in work-in-progress due to the lack of components available. However, this does not mean that all materials should be ordered as early as possible and stored on site, but rather that they should arrive just in time (Skjelbred et al., 2015).

The primary focus of logistics in construction is to improve coordination and communication between project participants during the design and construction phases, particularly in the materials flow control process (Agapiou et al., 1998). In prefabricated building systems, a higher level of coordination and frequent exchanges of information is necessary, due to the need to integrate different units of the same company, or sometimes to engage external suppliers of components (Čuš-Babič et al., 2014).

In order to reach a balance between on-site buffers of components and just-in-time deliveries. some conditions must be considered: uncertainty and variability in site conditions and upstream flows, distance to the supplier, lead time, the level of detail in the plans, and the amount of storage space on site (Skjelbred et al., 2015). The definition of the transportation batches is a key decision for controlling the flow of components and synchronising the production in both the prefabrication plant and assembly site. Those batches should be sized and designed according to the project, and are hard to be standardised in ETO production systems. In that case, a load plan needs to be produced for specific loads, describing what should go in the truck, and when it should arrive at the site.

Numerous research studies have pointed out the benefits of Building Information Modelling (BIM), especially by using 4D modelling to support production planning and control, such as testing alternative sequences of tasks (Chau et al., 2004), predicting logistics problems (Hartmann et al., 2008), detecting spatial conflicts between tasks (Akinci et al., 2002), monitoring progress discrepancies (Golparvar-Fard et al., 2009), improving site layouts (Ma et al., 2005) and analysing workspace congestion (Chavada et al., 2012). BIM enables a wide range of information to be stored and connected to a virtual building representation, which is produced by different project participants. This virtual model has the ability to store different types of information, including geometric, semantic and topological information (Schlueter and Thesseling, 2009).

However, none of those studies has addressed the process of planning and controlling logistics operations for prefabricated building systems such as loading and unloading components, movement of equipment, and control of site inventories. Moreover, little emphasis has been given to the interactions between traditional production planning and control systems with the management of site logistics in an organisational context. Indeed, most BIM tools are designed to handle permanent building objects, and temporary objects have received far less attention (Karan and Irizarry, 2015). Only a few and very specific aspects of logistics have been discussed so far, mostly related to the positional planning of inventories and workspaces. In fact, in most studies 4D models are simply a translation of the output of a CPM network (Jongeling and Olofsson, 2007) that contains only valueadding activities, a practice widely criticised by the Lean Construction Community.

The aim of this paper is to describe an application of BIM 4D modelling for supporting the process of planning and controlling logistics operations for prefabricated concrete structures. This application assumes that in ETO prefabricated building systems the 
manufacturing process must be pulled according to the assembly process status, similarly to what is prescribed in the Last Planner System ${ }^{\mathrm{TM}}$. This application supports decisionmaking in the definition of the loading operations that need to be carried out, considering the priorities established in the long terms plans, the existing inventories in the plant yard, and site constraints. This was based on an empirical study carried out in collaboration with a large company that delivers concrete prefabricated structures in Brazil.

\section{RESEARCH METHOD}

Design Science Research (DSR) was the research approach adopted in this investigation. The aim of DSR is to develop innovative solutions that solve practical problems and at the same time allow a theoretical contribution (Kasanen et al., 1993). Problems from real world are investigated and one of the research outcomes is the development of artefacts such as models, diagrams, plans, organisation structures, and information system designs (Lukka, 2003). The research process was divided into the following phases: understanding the problem, development of the artefact, and analysis and reflection. It was conducted in close collaboration with the concrete prefabrication company (named Company A), similarly to an action research process. Several learning cycles were undertaken during the implementation process. This research study is part of a broader research project that aims to implement improvements in the production system and assembly process of concrete prefabricated structures.

Company A is a company that delivers complete solutions of prefabricated concrete structures for building projects in Brazil, often involving customised components. This can be described as an Engineer-to-order production system. This research study was focused on the delivery of prefabricated concrete structures for a university campus, located in Porto Alegre, which corresponds to $67 \%$ of the total constructed area of the building. The components for this project were all produced in a prefabrication plant located $740 \mathrm{~km}$ away. This company was chosen because they had an improvement program based on the Lean Production Philosophy, and was interested in the use of BIM for managing logistics operations.

The study lasted 11 months, covering the whole period of site assembly. Multiple sources of evidence were used in this investigation: (i) unstructured interviews were carried out with different stakeholders from the concrete prefabrication company and from the construction company, such as the site managers from each company, assistants and crew leaders from the prefabricated contractor; (ii) document analysis, including 2D designs and activity plans, spreadsheets of load plans and components status report; (iii) participant observations in short-term planning meetings, involving representatives of both companies, with an average duration of 1 hour, to discuss the construction progress; (iv) meetings with site manager, with 30 minutes length, were performed during 26 site visits, for short-term plan discussions and planning load discussions, using 4D simulation to understand assembly sequence. Besides, three workshops involving the research team and company's representatives were carried out to create a discussion group, providing a common understanding of concepts and practices as well as diagnosis carried out on the construction site. In addition, two plant visits were performed at the company headquarters in Curitiba to understand the production process of components. 


\section{EMPIRICAL STUDY}

\subsection{D and 4D Modelling}

The modelling process was divided into two stages. First, a 3D model was produced, using the 2D structural design as a starting point. Then, a 3D model of the construction site was devised, including, besides the prefabricated components, some temporary facilities, pathways and main equipment. The codes used for identifying each prefabricated component in the structural design were used in the 3D model, as this is an important identification throughout all company controls. Figure 1 provides an example of the code used for identifying a component in a 2D drawing (a), and the attributes assigned to that component in the 3D BIM model. In this case, families of the component were created, by creating a specific ID for each of them.

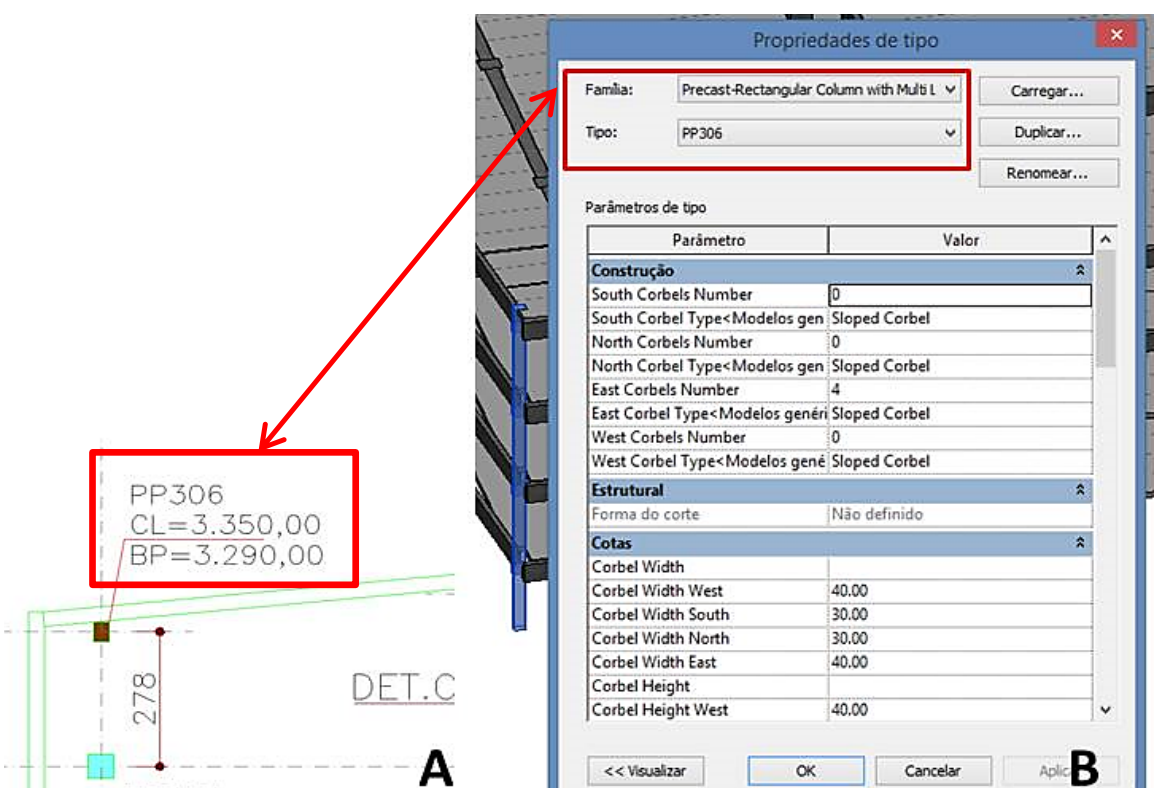

Figure 1 - Components Code in the 2D drawing (a) and in the BIM model (b)

The 4D model was generated in the Synchro Professional software, based on the schedule from the construction site The long-term plan provided by the company was used only as starting point for the creation of the activities schedule in the $4 \mathrm{D}$ simulation software. A coding system for the assembly activities was created, combining the position (axis) of the component, the type of component to be assembled (columns, beams or slabs) and the identification of the assembly stage. Figure 2 presents an example of the coding system.

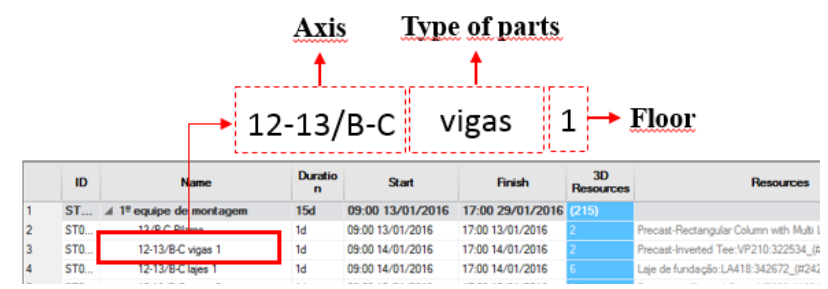

Figure 2 - Example of the coding system for site assembly activities

\subsection{Existing process for planning the load}

A key activity in logistics operations is planning the loads, based on the definition of transportation batches. It is worth noting that concrete prefabricated components should 
not be stored on site, i.e. the delivery date and the sequence of transportation batches should match the assembly date and sequence. In that context, the task of planning the loads becomes more critical than when is possible to site inventories. Before the improvements were implemented, this process was carried by manually matching the components described on 2D drawings and the site assembly schedule, in order to generate a daily list of the required components. In parallel, the production planning and control department from the plant should provide the components status report, containing updated information about the status of each component (e.g. not produced, produced, ready to ship). After that, the site manager should check if the required components would be ready on time for shipping. Then, the loads were planned based on the availability of the components.

Figure 3 represents schematically this process. The load plans were produced every fifteen days, containing approximately forty-five loads - each load had eight components on average. The load plans were sent to the planning and control department 15 days before they were required on site, in order to confirm the production of components and 2 days in advance to the expedition department to confirm the site assembly demand.

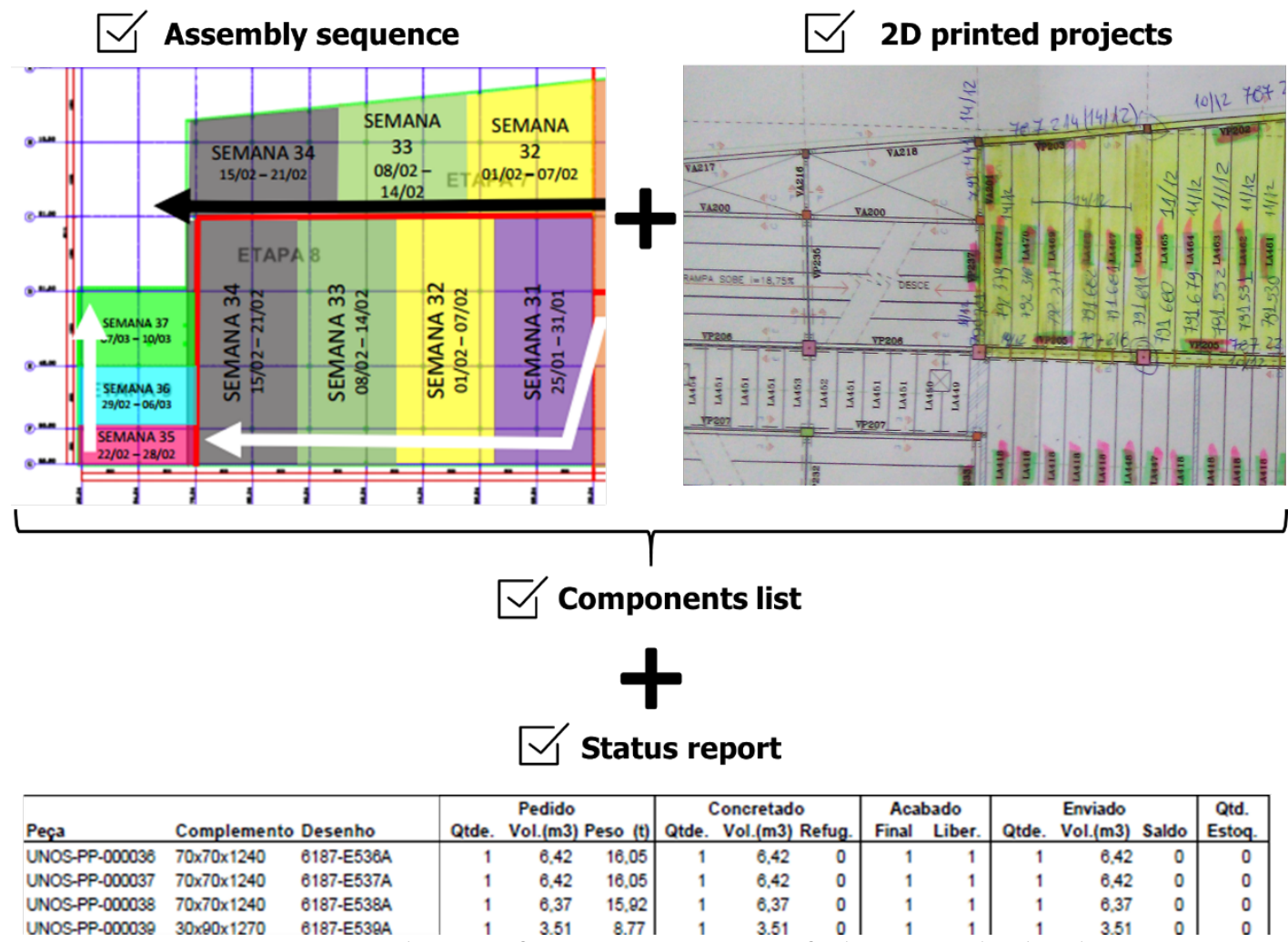

Figure 3 - Schema of existing process of planning the load

\subsection{Changes introduced in the process of planning the loads}

A major change in the process of planning the loads was the introduction of a 4D BIM model containing all necessary information about prefabricated concrete components. By assigning objects of the 3D model to each scheduled activity, planners could easily visualise the progress of the site-assembly process, and the batch size assigned to each crew, reducing the possibility of errors while planning the loads. Figure 4 represents the interface of the 4D BIM software, which displays a bar chart containing the activities to 
be performed on a given day, and the model containing geometric, semantic and topological information of each object of the model.

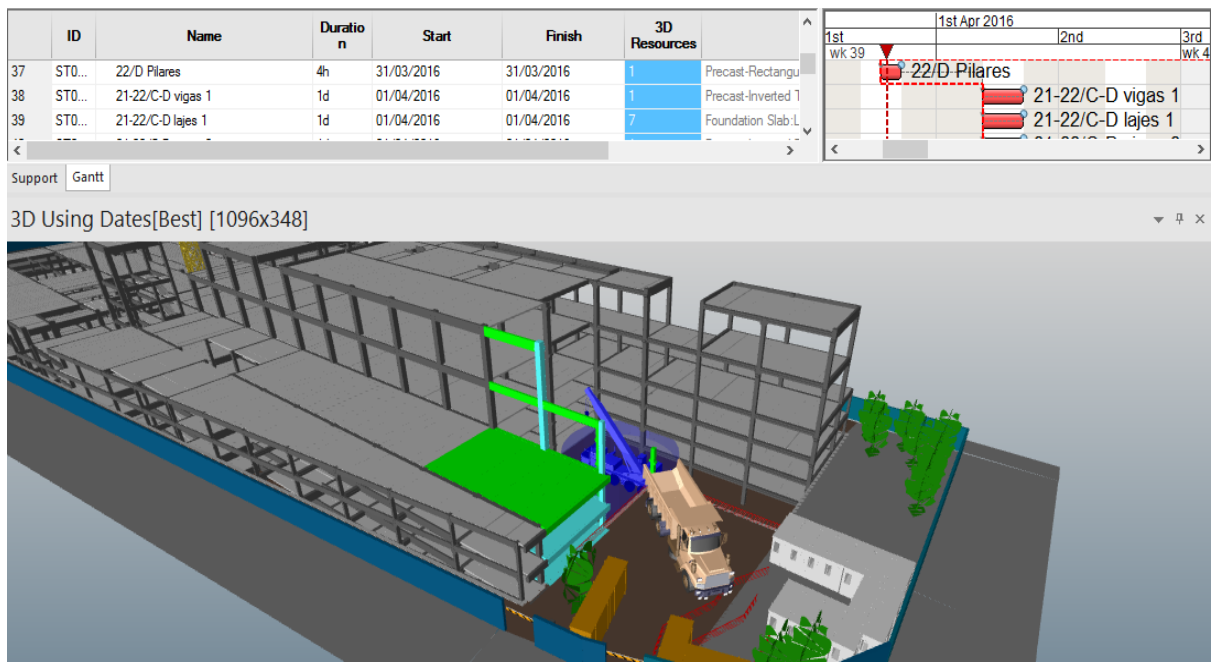

Figure 4 - Interface of the 4D BIM simulation software

An activity list was exported from the model in Synchro software, containing useful information for making decisions about planning the loads. Each line of this Microsoft Excel spreadsheet (Figure 5) relates to all types of components (such as columns, beams, slabs), in a specific location, during a specific period.

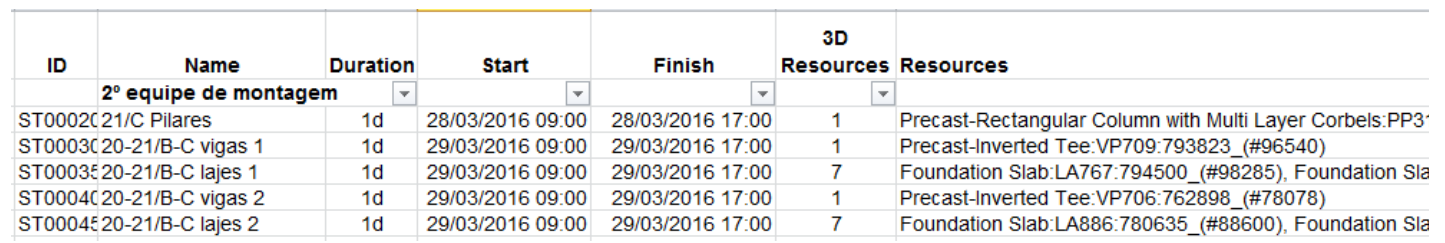

Figure 5 - Spreadsheet with list of activities and the assigned resources

The information from the production status report was included in this spreadsheet to analyse if the required components were ready to be shipped. The spreadsheet was designed for automatically update this information from the status report, creating a new tool for the process of planning loads. Error! Reference source not found. shows the information arrangement of the spreadsheet, highlighting (dashed line) the required inputs in terms of location axes and level.

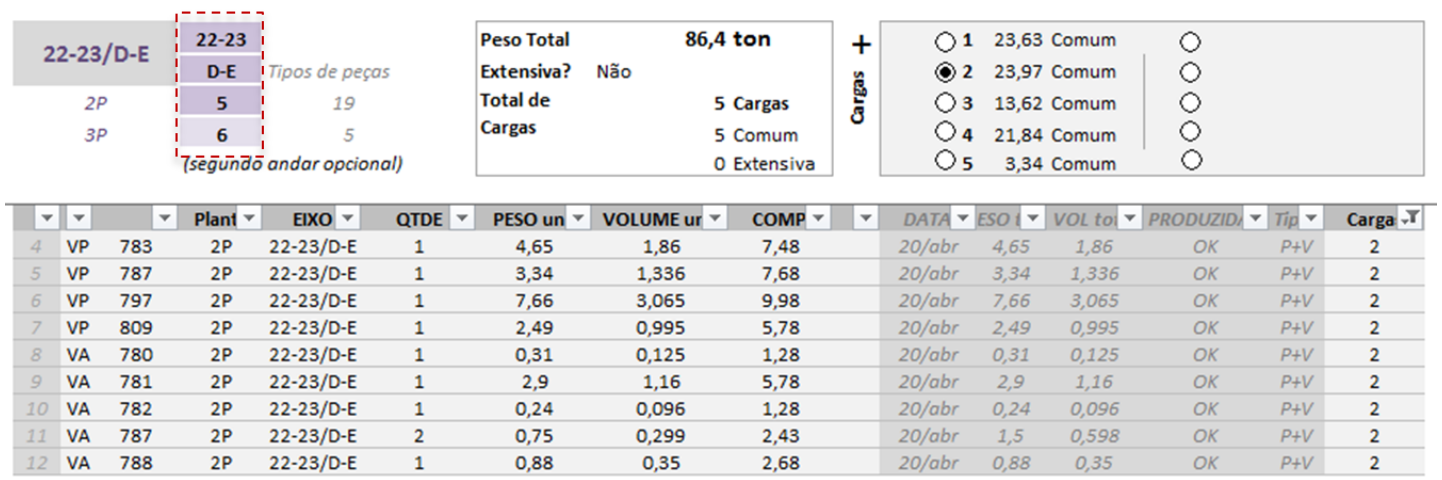

Figure 6 - Spreadsheet of planning the loads 
After using the tool, the site manager reported a 33\% reduction in the time spent on this activity. This happened because several non-value-adding activities were eliminated (e.g. the manual generation of the component list and the cross-comparison of information from the component list and component status report). This also contributed to the organisation of the information by the site manager, so that all information needed for planning the loads was in the same file.

By using BIM integrated with production data, the exchange and update of information became more reliable. There is a change in the availability of status information in real time. The plant delivered $95 \%$ of the requested loads on time, and the productivity of the assembly team has increased due to the reduction in the waiting time by components of the plant. The effective communication between the construction site and the manufacturing plant, made short-term plans more accurate, which then led to a reduction in the duration of the operation, also reducing delays and a lower demand for material buffering, as highlighted by Čuš-Babič et al. (2014).

The benefits of this application could more perceptible if the Last Planner System was used in its full potential. The use of $4 \mathrm{D}$ simulations has made easier the control of the assembly process (Figure 7) and reduced the time spent for this activity. In addition, there were improvements in the visualisation of the project, by making available geometric and topological information of the components.
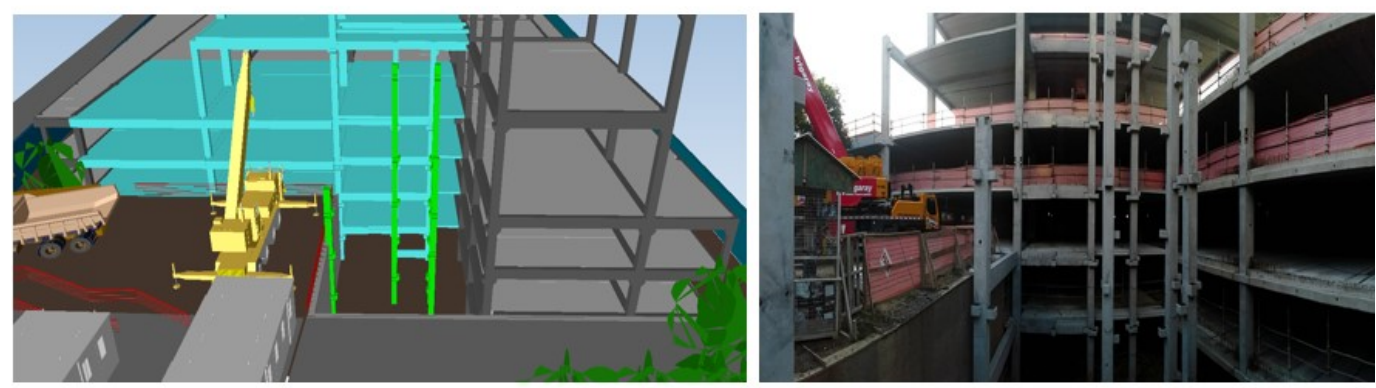

Figure 7 - Comparison between 4D simulation and real executed work

\section{CONCLUSIONS}

This research work pointed out the importance of planning loads in the context of Engineer-to-order prefabricated building systems, as part of logistics management. Planning the loads is also important to confirm the need for production of prefabricated elements and to control material flows, providing a clear definition of batches and assembly sequence.

The use of $4 \mathrm{D}$ models, including semantic information of components and critical equipment, has contributed to improve the understanding of the production process. The practice of updating this model during short and medium-term planning and control processes facilitates decision-making about logistic process both for the plant and for the construction site. The ability to exchange and update information increases the reliability and transparency of the process, supporting collaboration between different departments of the company (production, expedition, and assembly). Furthermore, the improvements in the process of planning the loads contributed to reduce delays in the delivery of components to assembly sequence, to reduce site inventories and ensure that the prefabrication plant produce only the necessary to attend the site demand. 


\section{ACKNOWLEDGMENTS}

We would like to thank the CNPq for the financial support for this research project and the company for the opportunity to develop this investigation.

\section{REFERENCES}

Agapiou, A., Clausen, L.E., Flanagan, R., Norman, G., Notman, D., 1998. The role of logistics in the materials flow control process. Constr. Manag. Econ. 16, 131-137.

Akinci, B., Fischer, M., Kunz, J., 2002. Automated generation of work spaces required by construction activities. J. Constr. Eng. Manag. 128, 306-315.

Chau, K.W., Anson, M., Zhang, J.P., 2004. Four-Dimensional Visualization of Construction Scheduling and Site Utilization. J. Constr. Eng. Manag. 130, 598-606.

Chavada, R., Dawood, N., Kassem, M., 2012. Construction workspace management: the development and application of a novel $\mathrm{nD}$ planning approach and tool. J. Inf. Constr. 17, 213-236.

Čuš-Babič, N., Rebolj, D., Nekrep-Perc, M., Podbreznik, P., 2014. Supply-chain transparency within industrialized construction projects. Comput. Ind. 65, 345-353.

Eastman, C., Teicholz, P., Sacks, R., Liston, K., 2011. BIM Handbook - A Guide to Building Information Modeling for Owners, Managers, Designers, Engineers, and Constractors, 2nd ed, John Wilet \& Sons, Inc. New Jersey.

Golparvar-Fard, M., Peña-Mora, F., Arboleda, C. a., Lee, S., 2009. Visualization of Construction Progress Monitoring with 4D Simulation Model Overlaid on TimeLapsed Photographs. J. Comput. Civ. Eng. 23, 391-404.

Hartmann, T., Gao, J., Fischer, M., 2008. Areas of Application for 3D and 4D Models on Construction Projects. J. Constr. Eng. Manag. 134, 776-785.

Jongeling, R., Olofsson, T., 2007. A method for planning of work-flow by combined use of location-based scheduling and 4D CAD. Autom. Constr. 16, 189-198.

Karan, E.P., Irizarry, J., 2015. Extending BIM interoperability to preconstruction operations using geospatial analyses and semantic web services. Autom. Constr. 53, 112.

Kasanen, E., Lukka, K., Siitonen, A., 1993. The Constructive Approach in Management Accounting Research. J. Manag. Account. Res. 5, 243-264.

Lukka, K., 2003. The Constructive Research Approach. Case study Res. Logist. Series B, 83-101.

Ma, Z., Shen, Q., Zhang, J., 2005. Application of 4D for dynamic site layout and management of construction projects. Autom. Constr. 14, 369-381.

Powell, D., Strandhagen, J.O., Tommelein, I., Ballard, G., Rossi, M., 2014. A new set of principles for pursuing the lean ideal in engineer-To-order manufacturers. Procedia CIRP 17, 571-576.

Schlueter, A., Thesseling, F., 2009. Building information model based energy/exergy performance assessment in early design stages. Autom. Constr. 18, 153-163.

Skjelbred, S., Fossheim, M.E., Drevland, F., 2015. Comparing Different Approaches to Site Organization and Logistics: Multiple Case Studies, in: 23rd Annual Conference of the International Group for Lean Construction. pp. 13-22.

Viana, D.D., 2015. Integrated Production Planning and Control Model for Engineer-toOrder Prefabricated Building Systems. PhD thesis, Universidade Federal do Rio Grande do Sul, Porto Alegre/RS 